\title{
Periferias urbanas, redes locais e movimentos sociais em fortaleza, ceará
}

\author{
Urban peripheries, local networks, and social \\ movements in fortaleza, ceará
}

\section{Periferias urbanas, redes locales y movimientos sociales en fortaleza, ceará}

\author{
iD Eduardo Gomes Machado \\ Universidade da Integração Internacional da Lusofonia Afro-Brasileira - Fortaleza - \\ Ceará - Brasil
}

(iD)

Alexandre Queiroz Pereira

Universidade Federal do Ceará - Fortaleza - Ceará - Brasil

Resumo: Este artigo discute como se constituem os movimentos sociais, particularmente nas periferias urbanas de grandes cidades brasileiras, evidenciando características fundantes e/ou essenciais à sua continuidade. Para tanto, apresenta linhas de força ou vetores teórico-empíricos nos quais se assentam a constituição e a continuidade de movimentos populares politicamente significativos, capazes de auferir conquistas com/para os públicos com os quais trabalham, focando o caso da Rede de Desenvolvimento Local, Integrado e Sustentável do Grande Bom Jardim (Rede DLIS do GBJ). O Grande Bom Jardim é uma periferia da cidade de Fortaleza, marcada por violências, vulnerabilidades sociais e violações de direitos, mas também pela presença ativa e variada de movimentos populares, desde pelo menos os anos 1980. Os dados e as análises aqui apresentados foram coletados a partir de uma inserção de longo curso na área, desde 2004, articulando observação participante, com viés etnográfico marcado pela cartografia social, análise documental, questionários e entrevistas. Percebe-se que a Rede DLIS do GBJ constitui dinâmicas e práticas cotidianas capazes de afirmar tensões criativas entre tradição e inovação; a constituição do território enquanto uma invenção política, 
articulada ao movimento social em rede e à agenda do desenvolvimento local, integrado e sustentável; a constituição reiterada de capacidades reflexivas, interpretativas e de lida continuada com situações problemáticas experienciadas no cotidiano urbano. Entende-se que essas linhas de força ou vetores teórico-empíricos têm sido essenciais à constituição de uma atuação política significativa, inclusive em suas implicações socioespaciais, na escala do território e da cidade.

Palavras-chave: Territórios Urbanos. Inovações Populares. Grande Bom Jardim.

Abstract: This article discusses how social movements are constituted, particularly in the urban peripheries of large Braziliancities, demonstrating the characteristics related to their foundation and/or essential for their continuity. To this end, lines of force or theoretical-empirical vectors are presented, which are the basis for the constitution and continuity of politically significant popular movements that are able to attain achievements both with and for their target public. The research focuses on the case of the Local Sustainable Development Network of Grande Bom Jardim (GBJ DLIS Network). The Grande Bom Jardim neighborhood on the periphery of the city of Fortaleza and is marked by violence, social vulnerability, and rights violations. However, since at least the 1980s, it has been home to active and varied popular movements. The data and analyses presented here were collected during a long-term insertion in the area, since 2004, and combine participant observation with an ethnographic bias with an emphasis on social cartography, document analysis, questionnaires and interviews. The results show that the GBJ DLIS Network has daily dynamics and practices capable of affirming creative tensions between tradition and innovation; the constitution of the territory as a political invention, linked to the networked social movement and the local, integrated and sustainable development agenda; and the repeated creation of reflective, interpretive and continuous skills to deal with the problematic situations experienced in urban daily life. These lines of force or theoretical-empirical vectors have been essential in the composition of significant political action and have socio-spatial implications on the scale of the territory and the city.

Keywords: Urban territories. Popular innovations. Grande Bom Jardim. 
Resumen: Este artículo discute cómo se constituyen los movimientos sociales, particularmente en las periferias urbanas de grandes ciudades brasileñas, evidenciando características fundamentales y/o esenciales para su continuidad. Para tanto, presenta líneas de fuerza o vectores teórico-empíricos en los que se asienta la constitución y la continuidad de movimientos populares políticamente significativos, capaces de obtener conquistas con/para los públicos con los que trabajan, específicamente el caso de la Red de Desarrollo Local, Integrado y Sostenible de Grande Bom Jardim (Red DLIS de GBJ). Grande Bom Jardim es una periferia de la ciudad de Fortaleza, marcada por violencias, vulnerabilidades sociales y violaciones de derechos, aunque también por la presencia activa y variada de movimientos populares, desde por lo menos los años 1980. Los datos y análisis que aquí se presentan se obtuvieron a partir de una inserción de largo curso en el área, desde 2004, articulando observación participante, con línea etnográfico marcado por la cartografía social, análisis documental, cuestionarios y entrevistas. Se percibe que la Red DLIS de GBJ constituye dinámicas y prácticas cotidianas capaces de afirmar tensiones creativas entre tradición e innovación; la constitución del territorio como una invención política, articulada al movimiento social en red y a la agenda del desarrollo local, integrado y sostenible; la constitución reiterada de capacidades reflexivas, interpretativas y de enfrentamiento continuado con situaciones problemáticas experimentadas en el cotidiano urbano. Se entiende que estas líneas de fuerza o vectores teórico-empíricos han sido esenciales para que se constituyera una actuación política significativa, incluso en sus implicaciones socioespaciales, en la escala del territorio y de la ciudad.

Palabras clave: Territorios urbanos. Innovaciones populares. Grande Bom Jardim.

Recebido para a publicação em 22 de fevereiro de 2020

Aceito para a publicação em 27 de março de 2020

Publicado em 
Periferias urbanas, redes locais e movimentos sociais em fortaleza, ceará Eduardo Gomes Machado - Alexandre Queiroz Pereira

\section{Introdução}

A instituição de um movimento social, e, mais do que isso, a sua permanência, particularmente quando efetiva formas de organização e atuação politicamente significativas, não está dada a priori, de modo automático. Cada movimento social é "irrepetível desde sempre e por todo o sempre" (MARQUES, 1967, p. 394), e, portanto, em cada uma das pequenas coisas cotidianas que o compõe há investimentos, belezas e potências, mas também fragilidades e delicadezas, inclusive a indicar que podem, a qualquer momento, deixar de existir. Isso é particularmente relevante ao considerarmos as precariedades, vulnerabilidades, violências e violações de direitos que atravessam os espaços urbanos periféricos e os agentes que os compõem.

Como se constituem os movimentos populares, particularmente nas periferias urbanas de grandes cidades brasileiras'? Mais do que isso, quais suas características fundantes e/ou essenciais? Características capazes de ancorar não somente sua emergência, mas também a continuidade marcada por uma atuação política que poderíamos nomear como competente? Avaliamos que essas questões permitem discutir elementos relevantes à análise dos movimentos sociais. Não é à toa que Melucci (1989) questiona como se institui um movimento social, como se coletivizam ações, particularmente ações coletivas duráveis. Esses questionamentos são relevantes, particularmente se entendemos que, para além das aparências mais imediatas, os movimentos sociais são marcados por espessuras, densidades e complexidades que cabe indiciar e discutir.

Se estamos falando de movimentos urbanos, a ideia de espessura vincula-se à percepção do urbano enquanto processualidade, na qual o pesquisador "se encontra sempre na situação paradoxal de começar pelo meio, entre pulsações", evidenciando que as ci-

\footnotetext{
1 Entendemos os agentes populares como segmentos sociais historicamente subalternizados, trabalhadores e não proprietários de terra e capital, marcados por violências, violações de direitos e vulnerabilidades múltiplas, particularmente associadas à colonialidade e à reprodução periférica do capitalismo.
} 
Periferias urbanas, redes locais e movimentos sociais em fortaleza, ceará Eduardo Gomes Machado • Alexandre Queiroz Pereira

dades são portadoras "de uma espessura processual", contrastando "com o meio informacional raso" (BARROS; KASTRUP, 2015, p. 58-59). O espaço urbano revela-se denso e complexo, e nele se condensam escalas temporais e espaciais diversas, perceptíveis através das "tramas finas das estruturas" urbanas de longa duração e das práticas cotidianas de interação face a face (BRAUDEL, 1965; PAIS, 2015).

Considerando essas questões, este artigo discute o que nomeamos como linhas de força ou vetores teórico-empíricos nos quais se assenta a constituição e a continuidade de movimentos populares politicamente significativos, capazes de auferir conquistas com/para os públicos com os quais trabalham. Para tanto, analisamos especificamente o caso da Rede de Desenvolvimento Local, Integrado e Sustentável do Grande Bom Jardim (Rede DLIS do GBJ), periferia da cidade de Fortaleza, considerando como linhas de força ou vetores teórico-empíricos: (1) as tensões entre tradição e inovação; (2) a constituição do território enquanto uma invenção política, articulado ao movimento social em rede e à agenda do desenvolvimento local, integrado e sustentável; (3) a constituição reiterada de capacidades reflexivas, interpretativas e de lida continuada com situações problemáticas.

Fortaleza é a quinta maior cidade brasileira, com população estimada em 2,7 milhões de pessoas (IBGE, 2019). O arco conformado por sua porção Sul mais distante do litoral e pelas áreas Sudoeste, Oeste e Noroeste conforma um espaço marcado por segregação socioespacial de larga escala, com ausência de regularização fundiária e grave vulnerabilidade social (MACHADO, 2017). Nesse contexto geográfico, até os anos 1950, a área ocupada pelos cinco bairros que atualmente compõem o chamado Grande Bom Jardim - Bom Jardim, Canindezinho, Granja Lisboa, Granja Portugal e Siqueira -, detinha características rurais ou periurbanas, composta por fazendas, sítios, carnaubais e olarias, e atravessada pelo Rio Maranguapinho. A partir dos anos 1960, a ocupação urbana da área vincula-se a dois grupos: (i) migrantes vindos do interior do estado do Ceará, famílias trabalhadoras, sem renda ou com 
Periferias urbanas, redes locais e movimentos sociais em fortaleza, ceará Eduardo Gomes Machado • Alexandre Queiroz Pereira

baixa renda, não proprietárias de terra e capital; (ii) ao mesmo tempo, famílias que ocupavam pedaços de terra em centralidades urbanas de Fortaleza, particularmente no setor conformado pela Aldeota (MACHADO, 2017), removidas em virtude da consolidação e ampliação de dinâmicas capitalistas de propriedade privada e mercantilização da terra urbana. Percebe-se que variadas lógicas socioespaciais confluem para a ocupação e produção desse espaço urbano (DIÁRIOS DE CAMPO, 2015-2020)2. Aos poucos, constituem-se comunidades e emergem loteamentos e mercados populares de terrenos e habitações, configurando dinâmicas de autoconstrução.

Ao mesmo tempo, a área também é reconhecida na cidade pela força dos movimentos sociais locais, evidenciando diferentes formas de associação, organização e atuação política popular, inclusive com participação de representações locais em conselhos de direitos e em conselhos gestores de políticas públicas, no âmbito da cidade ou do município (DIÁRIOS DE CAMPO, 2015-2020). Nesse sentido, consideramos que o movimento popular do Grande Bom Jardim, e particularmente a Rede, vem demonstrado capacidades de aprendizagem e de reconstituição reiterada das próprias formas sociais e práticas cotidianas, em contextos marcados por dinâmicas conflituais variadas, "diversificando suas estratégias de ação e combinando-as de forma criativa a partir das oportunidades e constrangimentos impostos pela conjuntura" (TATAGIBA; PATERNIANI; TRINDADE, 2012, p. 401).

Os dados e as análises aqui apresentados decorrem de uma inserção de longo curso na área do Grande Bom Jardim, em um contexto de interlocução entre agentes acadêmicos e populares, efetivando, em diferentes momentos, ações marcadas pela observação participante, pesquisa-ação, cartografia social, entrevistas, questionários e análise documental. Mobilizamos enfoques e categorias que dialogam com o que podemos nomear como tradições interpretativa e pragmática nas Ciências Sociais e Humanas, apresentando três linhas de força ou vetores teórico-empíricos. Para

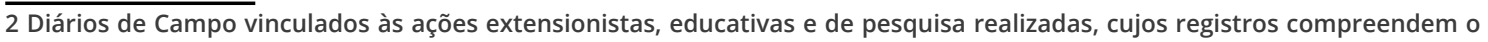
período de 2015 a 2020. 
Periferias urbanas, redes locais e movimentos sociais em fortaleza, ceará Eduardo Gomes Machado • Alexandre Queiroz Pereira

tanto, o artigo se estrutura, além desta Introdução, em mais três seções, além das Considerações Finais.

\section{O território como invenção política e contexto experiencial}

O Grande Bom Jardim tornou-se uma grande periferia urbana precária, onde reside parcela relevante da força de trabalho, ativa e inativa, que ocupa posições instáveis em circuitos inferiores da economia e em mercados formais e informais de trabalho na cidade e nos municípios vizinhos de Caucaia e Maracanaú.

Trata-se de uma população superior a 211 mil habitantes (IBGE, 2010) a conviver com extrema precariedade nos equipamentos, serviços e infraestruturas urbanas, com vulnerabilidades, violências e violações de direitos em diferentes escalas e dimensões. Esses cinco bairros estão, por exemplo, entre os 12 que detêm os piores Índices de Desenvolvimento Humano por Bairro (IDH-B) (IBGE, 2019) na cidade. Considerando-se dados de 2010, em torno de $84 \%$ das pessoas da área não tinham rendimento ou tinham rendimento até um salário mínimo (IBGE, 2010).

Nesse tecido de precariedade, demandas e conflitos, a Rede de Desenvolvimento Local, Integrado e Sustentável do Grande Bom Jardim (Rede DLIS do GBJ) foi instituída em 2003, como resultado de um processo de planejamento participativo e de pesquisa. Como desdobramento, efetuou-se um Diagnóstico Participativo, com abordagens etnográficas, envolvendo dezenas de pesquisadores populares, gerando dados e análises significativas (REDE DLIS, 2016, p. 10). Em 23 de dezembro de 2003, foi realizada a primeira "Conferência de Desenvolvimento Sustentável do Grande Bom Jardim", nela sendo instituída politicamente a Rede.

O processo tem continuidade nos anos seguintes e, entre 2003 e 2006, foram realizadas 18 assembleias da Rede DLIS, instituindo-se comitês locais por bairro, os quais realizaram 144 
Periferias urbanas, redes locais e movimentos sociais em fortaleza, ceará Eduardo Gomes Machado • Alexandre Queiroz Pereira

encontros no período, "contribuindo para o diagnóstico participativo" (REDE DLIS, 2016, p. 10). Entre novembro de 2004 e março de 2005, foram realizadas 17 assembleias dos Comitês Locais dos Bairros para indicar e eleger moradores para o Conselho Popular de Desenvolvimento Urbano, outra instância política constituída à época, com 255 integrantes tomando posse em março de 2005.

Em 2005, foi realizada a II Conferência de Desenvolvimento Sustentável do Grande Bom Jardim, aprovando "Planos Estruturantes para o desenvolvimento local dos bairros do Grande Bom Jardim", consolidando a elaboração final da "Política de Desenvolvimento Sustentável do Grande Bom Jardim", pensada como estratégia para vinte anos de atuação da Rede, até 2025 (REDE DLIS, 2016). Essa política de desenvolvimento sustentável agrega cinco planos estruturantes, cada um dos quais com demandas e projetos agregados: jardim justo e includente; jardim do bem viver sustentável; jardim solidário e competitivo; jardim cooperativo e da cidadania; jardim brincante (REDE DLIS, 2016). Também cabe indicar a realização das III e IV Conferências, em 2006 e em 2015 (REDE DLIS, 2016).

Nesse contexto, cabe considerar que o próprio Grande Bom Jardim é, em certa medida, uma invenção territorial, posto que não existe formalmente na estrutura institucional do município ou da cidade, embora venha sendo legitimado e reconhecido por instituições e gestões variadas, em diferentes escalas físico-geográficas e político-administrativas. Tampouco, se trata propriamente de uma denominação que emerge da vida ordinária dos agentes que residem no território, como seria o caso, por exemplo, da Grande Messejana, também em Fortaleza. Trata-se mais propriamente de uma invenção político-técnica dos agentes envolvidos nos processos anteriormente indicados, buscando fortalecer sua atuação junto ao Estado, envolvendo variadas estratégias e táticas políticas, inclusas pressões, demandas e monitoramento de sistemas e políticas públicas. 
Periferias urbanas, redes locais e movimentos sociais em fortaleza, ceará Eduardo Gomes Machado • Alexandre Queiroz Pereira

Entretanto, um elemento importante a considerar é o de que essa invenção territorial se tornou possível ou viável em virtude do que podemos nomear como contexto territorial prévio.

Almeida (2014, p. 28) afirma:

[...] o papel dos grupos pastorais e das congregações missionárias atuantes na região, desde início da década de 198[0], como fomentadores do potencial organizacional dos moradores locais e forte contribuinte para a composição do tecido social.

Para além da (ausência de) organização e estruturação territorial formal da área, pelo Estado, até pelo menos o início dos anos 1980, há uma territorialização comunitária muito influenciada pelas práticas e místicas religiosas de congregações católicas progressistas atuantes, vinculadoras de dinâmicas de mobilização social e de associação comunitária. 
Periferias urbanas, redes locais e movimentos sociais em fortaleza, ceará Eduardo Gomes Machado • Alexandre Queiroz Pereira

Figura 1 - Comunidades de Pertença - Grande Bom Jardim

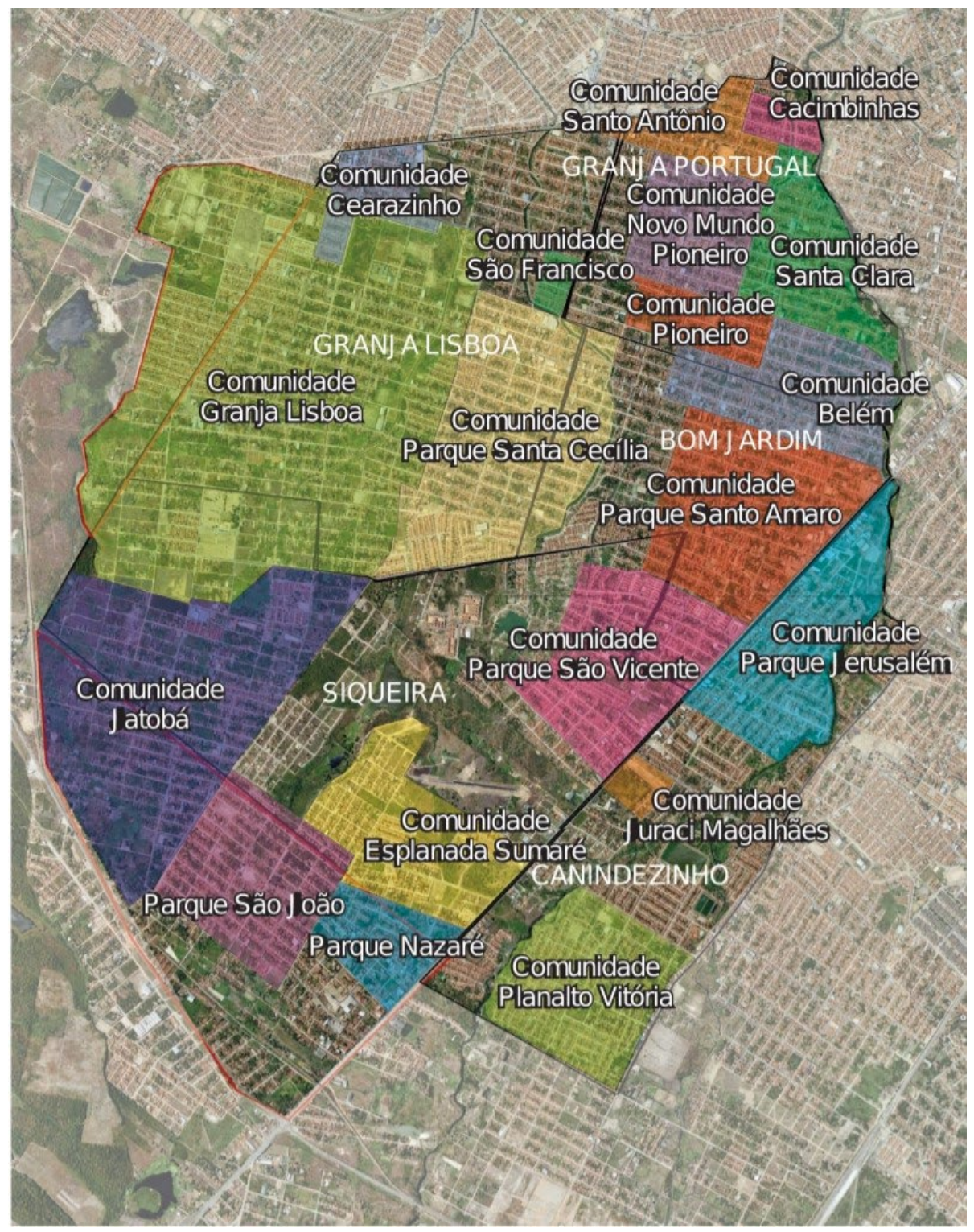

Fonte: Adaptado de Almeida (2014, p. 28).

A Figura 1 evidencia como os nomes de bairros ou comunidades materializaram as práticas/místicas das congregações religiosas, em sua grande maioria com "nomes de santos" ou outros "referentes católicos": Santa Clara, Santa Paula Frassinetti, Santa Cecília, Santo Amaro, São Vicente, São Francisco de Assis, Santo Antônio, Parque Jerusalém, Canindezinho, Belém, Parque São João, Parque Nazaré, Jardim Nazaré (ALMEIDA, 2014). Ao mesmo tempo, 
Periferias urbanas, redes locais e movimentos sociais em fortaleza, ceará Eduardo Gomes Machado • Alexandre Queiroz Pereira

há indícios, pelo menos nos territórios das comunidades Granja Lisboa e Jardim Jatobá, da influência de terreiros de umbanda, operando na constituição de micro e nano territórios, transitando entre a visibilidade e a invisibilidade, considerando os vetores de ruas e as comunidades específicas e gerando sentimentos/sentidos de vinculação e pertença (DIÁRIOS DE CAMPO, 2015-2020). Desse modo, esses referentes indiciam redes de relações que, mesclando elementos formais e informais, evidenciam espaços apropriados e vividos através de políticas cotidianas da vizinhança e da proximidade, capazes de assentar e reproduzir interações cotidianas, redes de apoio e solidariedade e compromissos mútuos.

Portanto, há um contexto territorial prévio, que se inscreve na própria construção do movimento popular na área, e que, mais do que embasar, permite e induz essa invenção política. Cabe destacar que compreendemos o território enquanto espaço politicamente controlado e regulado, onde os próprios agentes populares adquirem ou intencionam adquirir a capacidade de regular certas áreas, exercendo poder com implicações espaciais (SOUZA, 2009; SAQUET, 2013). Nesse sentido, enquanto espaço apropriado e produzido, gera redes e/ou relações que se reconstituem continuamente, envolvendo diferentes escalas, agentes e fluxos materiais e imateriais (SAQUET, 2013). Ao mesmo tempo, também cabe compreender o território enquanto espaço vivido, demarcado afetivamente, evidenciando convivência continuada e minimamente próxima dentre um conjunto de agentes urbanos.

Com a instituição da Rede, o movimento popular intenciona fortalecer seu poder territorial, sua capacidade de influenciar a apropriação e a produção social do espaço urbano, inclusive considerando que, nesse período, incorpora e passa a operar - teórica e praticamente - com categorias como o direito à cidade, a produção social do espaço urbano e o planejamento urbano (DIÁRIOS DE CAMPO, 2015-2020; MACHADO, 2011). Nesse sentido, a constituição do território do GBJ se articula a projetos partilhados, os quais, afirmando um território desejado/buscado, mobilizam e articulam identidades, intersubjetividades, contextos existenciais 
Periferias urbanas, redes locais e movimentos sociais em fortaleza, ceará Eduardo Gomes Machado • Alexandre Queiroz Pereira

e horizontes de sentido que agregam expectativas, motivações e contrapartidas, bem como estratégias e ações para efetivá-lo. Assim, trata-se de um projeto que reconstitui continuamente concepções, imagens e imaginários que, mesmo subalternos e/ou minoritários, não somente distinguem-se, mas se contrapõem aos hegemônicos, mediando ações políticas e práticas urbanas cotidianas. Isso é perceptível, por exemplo, na contestação do imaginário hegemônico na cidade, demarcado por estigmas territoriais (MOURA, 2012). Desse modo, à imagem e imaginário hegemônico na cidade, marcados por violências criminais e delinquenciais, a Rede vai contrapondo o território do bem viver, do desenvolvimento sustentável, da arte e cultura, das tradições populares, da mobilização social, da economia solidária, dentre outros referentes (DIÁRIOS DE CAMPO, 2015-2020).

O movimento popular do Grande Bom Jardim, e mais especificamente a Rede, tem sido capaz de gerar capacidades para redefinir material e imaterialmente os espaços urbanos que constituem o território, impactando ocupação, uso, acesso, construção, posse e propriedade de diferentes parcelas da terra urbana. Essas capacidades de controlar e regular o espaço local, os fluxos e os fixos existentes, mesmo fragmentárias, minoritárias e latentes, se revelam, por exemplo, na força do movimento na implantação local do Centro Cultural Bom Jardim (CCBJ), um equipamento público de grande porte, na instituição do Parque Urbano Lagoa da Viúva, constituindo uma área ambientalmente protegida, e na efetivação de políticas para a Zona Especial de Interesse Social do Grande Bom Jardim (Diários de campo, 2015-2020).

\section{Ciclos do movimento popular no Grande Bom Jardim, tradições e inovações}

Já com mais de 15 anos de atuação, a Rede é uma experiência duradoura de ação coletiva, política e tecnicamente competente 
Periferias urbanas, redes locais e movimentos sociais em fortaleza, ceará Eduardo Gomes Machado • Alexandre Queiroz Pereira

em seus campos de atuação (MACHADO; FAUSTINO, 2018), cabendo perguntar como se constituiu, e, mais do que isso, o que explica essa capacidade de atuação e persistência.

A emergência e a instituição da Rede se inserem em um processo mais amplo de constituição do movimento popular do Grande Bom Jardim, demarcado pelo que podemos nomear como ciclos (DIÁRIOS DE CAMPO, 2015-2020; ALMEIDA, 2014; CARLOS, 2014). Os ciclos envolvem temporalidades distintas em toda sua potência histórica, evidenciando a constituição de, mais do que repertórios de ação (TILLY, 2010), de regimes de ação, engajamento e associação (CEFAÏ, 2009). Nesse sentido, a trajetória do movimento, rastreada pelo menos desde os anos 1970, agrega quatro gerações de ativistas e militantes em atuação, e seis ciclos, cabendo considerar que não obrigatoriamente a emergência de um ciclo significa o encerramento do ciclo anterior. Desse modo, há possibilidade de coexistência de ciclos ou, pelo menos, da permanência de características centrais a cada ciclo, embora não mais hegemônicas. Assim, cabe destacar a emergência, em cada ciclo, de categorias força/vetores teórico-empíricos relevantes, compondo tradições e repertórios de instituições, disposições e práticas localmente acumuladas, mobilizadas e operadas.

O primeiro ciclo envolve as associações comunitárias tradicionais enquanto formas associativas, e a presença de lideranças mais ou menos autônomas, voltadas ao atendimento dos problemas urbanos vivenciados pelas comunidades, buscando melhorias, serviços e obras variadas, atuando sob uma lógica de interpelações e compromissos mútuos com órgãos e políticos profissionais, no limite de uma lógica clientelista de atuação, sem contestação ou alternativa até meados dos anos 1980 (DIÁRIOS DE CAMPO, 2015-2020). Apesar das limitações, foram importantes e cumpriram papéis significativos quanto à certa organização, publicização e conquista de melhorias urbanas, evidenciando dinâmicas associativas e de luta por direitos de modo pioneiro.

O segundo ciclo, que se articula à presença de variadas congregações religiosas progressistas, algumas influenciadas pela 
Periferias urbanas, redes locais e movimentos sociais em fortaleza, ceará

Eduardo Gomes Machado • Alexandre Queiroz Pereira

Teologia da Libertação, é aqui denominado de comunidades irmãs, constituindo-se, pouco a pouco, enquanto forma associativa e de atuação política alternativa às associações comunitárias tradicionais, que operavam no limite de modos clientelistas de pactuação com agentes políticos formais (ALMEIDA, 2014). Emerge, então, a rede de comunidades enquanto modo associativo significativo, dotando de relevância o trabalho de base e a autoconscientização dos moradores, para além de uma hierarquia estanque que, no ciclo anterior, assentava nas lideranças das associações a força da atuação política. Nesse sentido, cabe a referência à atuação das Irmãs Salvatorianas, congregação que se insere na área em 1980. As Irmãs Salvatorianas são agentes importantes na instituição de um conjunto de primeiras Escolas Comunitárias na área, no início dos anos 1980, buscando suprir, mesmo parcialmente, a ausência de escolas públicas. Nesse processo, constituem-se vínculos e formas associativas inovadoras, e, ao mesmo tempo, são formados - teórica e praticamente - professores e lideranças relevantes ao movimento comunitário e popular local, algumas ainda em atuação. Esse processo formativo ocorreu sob a égide de educadores progressistas e, particularmente, da educação popular em Paulo Freire, o que passará a compor as tradições do movimento popular comunitário local a partir de então, revelando-se bastante relevante à conformação da Rede (MACHADO, 2018).

O terceiro ciclo é aqui denominado comunidades de comunidades, e se vincula à atuação da Congregação Missionários Combonianos, a partir de 1987-1988 (ALMEIDA, 2014), caracterizando-se pela instituição de "uma rede de relações que foi sendo criada e administrada no interior 'das comunidades'", e, ao mesmo tempo, evidenciando uma "autoconstituição coletiva popular envolvendo a construção de 'sentidos partilhados' e de modos próprios de sociabilidade" (CARLOS, 2014, p. 59). Essa configuração assume centralidade nos processos de "coletivização das ações", tendo como elementos fundantes a reconstituição reiterada de sentimentos de pertença e de vínculos, pactuações e compromissos mútuos a partir da convivência pautada na vizinhança, na 
Periferias urbanas, redes locais e movimentos sociais em fortaleza, ceará

Eduardo Gomes Machado • Alexandre Queiroz Pereira

proximidade, no partilhar de sentidos, valores e intenções e no entrosamento processual e coletivamente constituído. Nesse sentido, a ideia de "comunidades de comunidades" pode ser entendida como uma ideia-força que evidencia, articulando religião/fé e política, uma:

[...] espécie de antepassado do pressuposto assumido pela organização social em rede de hoje, preocupada com a integração dos bairros a partir de suas organizações locais e com a ligação com outros segmentos e setores da cidade. (ALMEIDA, 2014, p. 134)

O quarto ciclo envolve a emergência das organizações da sociedade civil, com destaque para o Centro de Defesa da Vida Herbert de Sousa (CDVHS) e o Movimento de Saúde Mental Comunitária do Bom Jardim (MSMCBJ), criados respectivamente em 1994 e 1996, conformando outras estratégias de reconstituição do tecido associativo local, das configurações organizacionais e da atuação política. Esse ciclo agrega categorias força significativas ao movimento popular comunitário local, cabendo destacar: (a) a centralidade da articulação entre política e técnica, evidenciada na aproximação reiterada com agentes acadêmicos e técnico-profissionais, fomentando a geração, incorporação e operação de dados qualitativos/quantitativos e análises que subsidiem a atuação política; (b) a valorização simultânea de conhecimentos, saberes e habilidades científico/técnicos e populares; (c) a articulação entre planejamento democrático e participativo, gestão coletiva, avaliação continuada e pesquisa; (d) a inscrição das demandas, das lutas específicas e dos processos de participação política e de controle social em uma concepção/proposta concreta de desenvolvimento local sustentável do Grande Bom Jardim (DIÁRIOS DE CAMPO, 2015-2020).

O quinto ciclo, que podemos aqui nomear como redes de agentes populares, inscreve, em uma configuração organizacional inovadora, a densidade e a complexidade que o movimento popular comunitário vai carreando, dotando de uma forma con- 
Periferias urbanas, redes locais e movimentos sociais em fortaleza, ceará Eduardo Gomes Machado • Alexandre Queiroz Pereira

creta a atuação conjunta, envolvendo um complexo de agentes populares que compõem o tecido associativo local e são politicamente atuantes. Nesse quinto ciclo, destaca-se a Rede DLIS do GBJ, enquanto uma instância de articulações de agentes e lutas, ou um complexo de movimentos, instituída em dezembro de 2003, como resultado de uma pesquisa e um processo participativo de grande escopo, a partir do qual se constituiu uma política de desenvolvimento sustentável local, com a realização de quatro conferências nos últimos quinze anos. Partilham um entendimento comum da unidade geográfica da região, como estratégia de potencializar a luta por direitos, e, ao mesmo tempo, baseiam a atuação em conhecimentos e análises consistentes, revelando a pesquisa enquanto fio condutor essencial.

A Figura 2 apresenta a delimitação dos bairros que compõem o Grande Bom Jardim, indicando a localização geográfica das componentes da Rede em $2017^{3}$.

3 Atualmente, a Rede possui 28 componentes, inclusos sete coletivos culturais de juventudes. 
Periferias urbanas, redes locais e movimentos sociais em fortaleza, ceará Eduardo Gomes Machado - Alexandre Queiroz Pereira

Figura 2 - Rede de Desenvolvimento Local do Grande Bom Jardim - localização das componentes

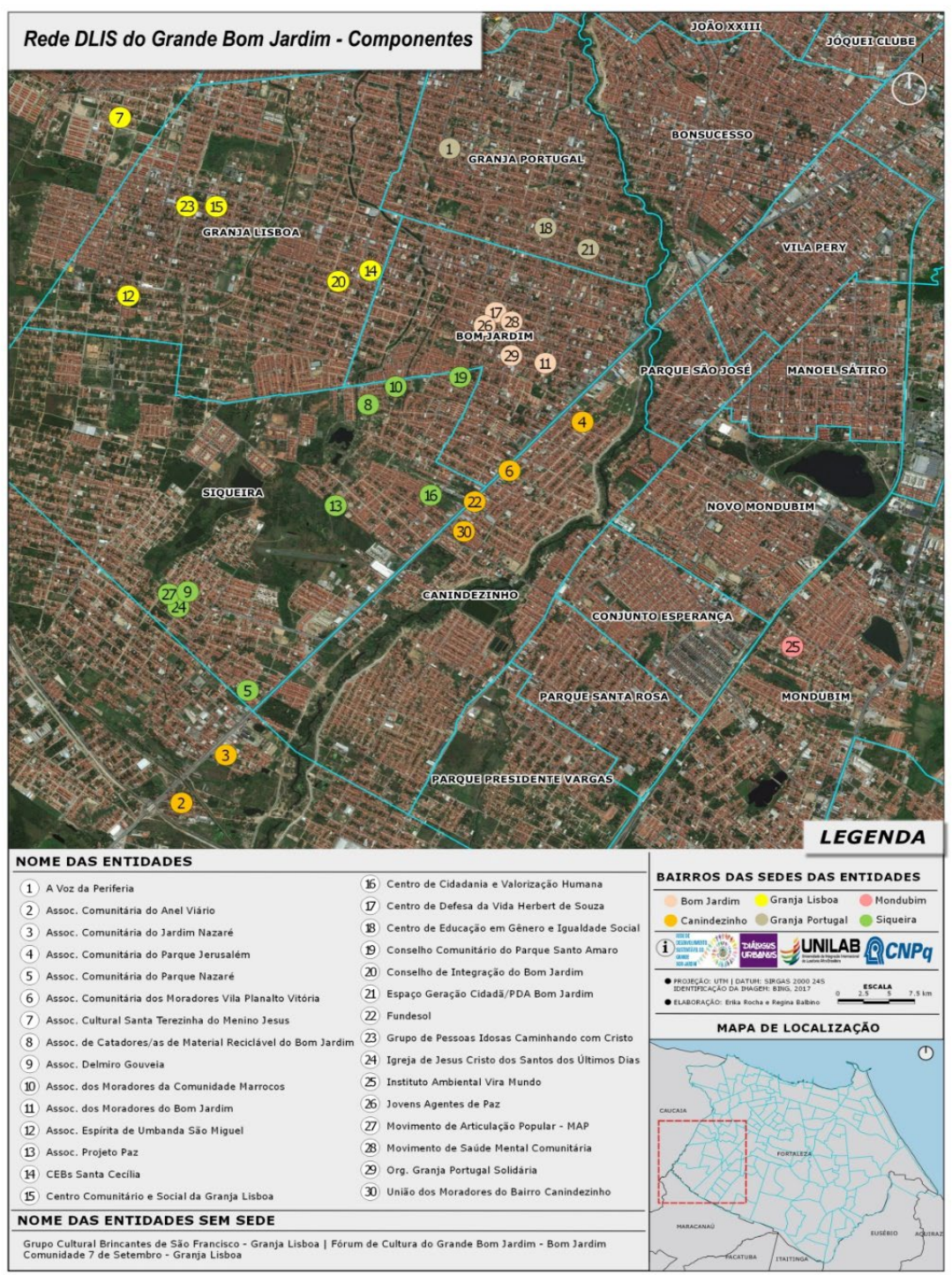

Fonte: Machado e Faustino (2018, p. 27).

O sexto ciclo envolve a emergência dos coletivos de juventudes, a partir de 2013, ganhando força no contexto das ocupações das escolas de ensino médio do território, em 2016; configurando uma articulação inovadora entre estética e política, com diferentes linguagens artísticas sendo mobilizadas e operadas; evidenciando novos modos de fazer política e de fazer a cidade (AGIER, 2015), com destaque para a ocupação e uso de espaços públicos urbanos e espaços coletivos de uso comum. 
Periferias urbanas, redes locais e movimentos sociais em fortaleza, ceará

Eduardo Gomes Machado • Alexandre Queiroz Pereira

A breve apresentação dos ciclos vivenciados pelo movimento popular-comunitário no Grande Bom Jardim permite intuir como a Rede é herdeira de um patrimônio social, político e estético significativo, sendo capaz de mobilizar, incorporar e vivenciar tal patrimônio nas experiências cotidianas (DIÁRIOS DE CAMPO, 2015-2020).

Mais do que isso, avaliamos que a Rede tem conseguido efetivar uma dinâmica cotidiana marcada por tensões criativas entre tradições e inovações, e, dessa forma, o cotidiano não é entendido aqui como "aquilo que sucede habitualmente e, nesse sentido, têm o significado de banalidade, monotonia" (PAIS, 2015, p. 77). Ao contrário, avalia-se que, no cotidiano, ocorre "o cruzamento de múltiplas dialéticas entre o 'rotineiro' e o 'acontecimento'", agregando o banal/insignificante e o histórico/original/significativo ( $p$. 76). Assim, as experiências cotidianas não se reduzem "ao que repetitivamente se passa, dia a dia, de forma rotineira e passiva", à "banalidade da vida", aos seus "aspectos triviais, monótonos e repetitivos", constituindo-se também enquanto "lugar[es] de inovação", de recusa, reorganização e transformação social, com "riquezas ocultas" sob "a aparente pobreza e trivialidade da rotina" (p. 79-80).

\title{
Mediando experiências e configurando sistemas de ação
}

\author{
A Rede continuamente reconstitui formatos e dinâmicas de fun- \\ cionamento e gestão (Diários de campo, 2015-2020). Atualmente, \\ se estrutura em comissões e fóruns - articulação; meio ambiente, \\ urbano e zonas especiais de interesse social; proteção às crianças \\ e aos adolescentes; fórum de cultura; fórum de juventudes -, que \\ se reúnem sistematicamente, ocorrendo, também, uma reunião \\ geral mensal, com todos os participantes, e um encontro anual \\ de planejamento, monitoramento e avaliação. Nesse momento, \\ agrega 28 componentes - dentre associações comunitárias, orga-
}


Periferias urbanas, redes locais e movimentos sociais em fortaleza, ceará

Eduardo Gomes Machado • Alexandre Queiroz Pereira

nizações da sociedade civil, coletivos de juventudes e culturais e grupos religiosos -, e está prestes a realizar o Encontro Anual de 2020.

Cabe falar em um movimento social em Rede, constituindo reiteradamente reagrupamentos "mais ou menos fluidos, em torno de situações problemáticas a serem resolvidas, pondo em jogo uma 'experiência criadora"' ao efetivar "dinâmicas de definição e resolução de situações problemáticas" (CEFAï, 2009, p. 1921; DIÁRIOS DE CAMPO, 2015-2019). Desse modo, evidencia-se como uma "inteligência cooperativa", que: [...] sustenta, distribui e configura a experiência dos atores, o que comanda também as modalidades de engajamento na ação coletiva e o que pereniza as invenções e emergências da vida dos públicos. (CEFAÏ, 2009, p. 22).

Assim, ao lidar com situações problemáticas, a Rede constitui-se enquanto "mediação de uma experiência coletiva (DIÁRIOS DE CAMPO, 2015-2020; CEFAï, 2017).

Nesse sentido, a "definição da situação problemática não é apenas uma questão de criatividade, mas também de instituição" (CEFAï, 2017, p. 193), posto que o "trabalho de definição da situação problemática" requer a constituição e a operação de instituições e disposições capazes de agenciar "um poder de ação", capazes de efetivar "um esforço de resolução" (CEFAï, 2017, p. 189). Dessa forma, é possível dialogar com Melucci (1989, p. 51) quando afirma a compreensão dos movimentos sociais enquanto "sistemas de ação".

A Rede tem sido capaz de constituir-se enquanto um "sistema de ação" que agrega orientações e significados singulares, efetivando convergências, sem desconsiderar a diversidade que a atravessa, considerando que há "tipos diferentes de comportamento", para além de uma "aparente unidade" absoluta (MELUCCI, 1989, p. 56). Desse modo, compreendemos, com Melucci (1989, p. 61), que os movimentos sociais contemporâneos se constituem enquanto "uma rede de pequenos grupos imersos na vida cotidiana que requerem um envolvimento pessoal na experimentação e na prática 
Periferias urbanas, redes locais e movimentos sociais em fortaleza, ceará

Eduardo Gomes Machado • Alexandre Queiroz Pereira

da inovação cultural". De modo similar, Diani (1992, p. 1) e Diani e Bison (2004, p. 282) afirmam os movimentos enquanto redes que, envolvendo uma pluralidade de agentes - individuais, coletivos e institucionais -, inseridos em configurações locais específicas e experienciando conflitos singulares, constituem, de modo minimamente continuado e cumulativo, repertórios de ação, padrões de aliança e estruturas organizacionais que permitem colaborações sustentadas.

Uma experiência significativa no âmbito da Rede vincula-se à luta pela regulamentação do Plano Diretor Participativo de Fortaleza (MACHADO, 2011). Em parceria com o Programa de Educação Tutorial (PET), do Departamento de Arquitetura, Urbanismo e Design (DAUD) da Universidade Federal do Ceará (UFC), através da comissão ZEIS, Moradia Digna e Meio Ambiente da Rede e agregando as comunidades integrantes da mancha da Zona Especial de Interesse Social (ZEIS) do Bom Jardim (Nova Canudos, Marrocos, Paz e Pantanal), realizou-se a pesquisa "Diagnóstico Comunitário, a Comunidade que Temos", como parte do processo de elaboração comunitária, colaborativa e participativa do Plano Popular da ZEIS Bom Jardim. Cabe destacar que a mobilização no GBJ, e em outras ZEIS de Fortaleza, foi fundamental para que, logo após a publicação do Plano Popular das ZEIS do GBJ, a prefeitura efetuasse a regulamentação e iniciasse o processo de constituição dos conselhos gestores.

Além disso, desde 2015, a Rede DLIS do GBJ vem construindo e consolidando uma rede de articulação colaborativa e parceria com a Universidade da Integração Internacional Afro-Brasileira (UNILAB), através de projetos de pesquisa e de extensão. Entre 2017 e 2018, esta parceria concebeu, desenvolveu e consumou a pesquisa Perfil da Rede de Desenvolvimento Local, Integrado e Sustentável do Grande Bom Jardim. 
Periferias urbanas, redes locais e movimentos sociais em fortaleza, ceará

\section{Considerações finais}

Ao nos referirmos aos movimentos sociais, considerando convergências dentre algumas das principais tradições analíticas, e, particularmente, entre enfoques "objetivistas" e "subjetivistas", avalia-se que "[eles] não surgem pela simples presença de desigualdade, nem resultam diretamente de cálculos de interesses ou de valores", resultando "tanto [d]a ação estratégica, crucial para o controle sobre bens e recursos que sustentam a ação coletiva, quanto [d]a formação de solidariedades e identidades coletivas" (ALONSO, 2009, p. 72).

A essas interpretações, agregamos a lida com situações problemáticas enquanto elemento essencial à constituição da Rede. Esta vem constituindo-se enquanto uma forma associativa e de atuação política inovadora, com uma agenda política consistente e continuada, que articula o desenvolvimento local do Grande Bom Jardim ao direito à cidade e aos direitos humanos, atuando de modo imediato, emergencial, em médio e longo curso no enfrentamento às múltiplas vulnerabilidades, violências e violações de direitos vivenciadas pelas populações locais. Desse modo, constitui um ator coletivo unificado que se apresenta publicamente como defensor de um projeto político singular - o desenvolvimento local, integrado e sustentável do/no território -, ao qual se vinculam diferentes demandas e agentes, efetuando ações bastante variadas.

Cabe falar, portanto, em um Movimento Social em Rede (CARLOS, 2011), assumindo "como premissa que as relações (ou laços) sociais estabelecidos por indivíduos, atores coletivos, associações ou organizações e instituições (e entre eles) constituem o elemento por excelência de estruturação da vida social" (p. 154). Mais do que isso, a Rede consegue constituir-se enquanto "meios de sociabilidade, nos quais emergem ocasiões de encontro que moldam as formas de coexistência", evidenciando processos complexos e intensos de aprendizagem, invenção e inovação, os quais evidenciam conjunturas práticos sensíveis "que fixam hábitos de 
Periferias urbanas, redes locais e movimentos sociais em fortaleza, ceará Eduardo Gomes Machado • Alexandre Queiroz Pereira

cooperação e de conflito" e "fornecem parâmetros de experiência cognitiva e normativa", constituindo modos de "agenciamentos de objetos, normas e pessoas" (CEFAÏ, 2009, p. 18-19; DIÁRIOS DE CAMPO, 2015-2019).

Por fim, cabe destacar que a estratégia de invenção territorial vem conseguindo reposicionar essa área no contexto do planejamento, da gestão e das lutas políticas na cidade de Fortaleza, revelando que a Rede exerce poder com implicações espaciais (SOUZA, 2009; SAQUET, 2013). Inclusive se consideramos o Grande Bom Jardim enquanto espaço vivido, onde convive, de modo continuado e próximo, um complexo de variados agentes urbanos, estabelecendo vínculos e relações sociais. Nesse sentido, a estratégia de desenvolvimento local do território parece deter potências múltiplas, mesmo se considerarmos que a produção de formas/substâncias socioespaciais alternativas, e sua inscrição no espaço urbano citadino e local, requer contraposições a estruturas e dinâmicas urbanas hegemônicas, operantes em longa e média duração e às quais se associam dimensões conflituais complexas.

\section{Agradecimentos}

Os autores agradecem ao CNPq, considerando a Chamada CNPq/ MCTI No 25/2015 Ciências Humanas, Sociais e Sociais Aplicadas, com vigência de dezembro de 2015 a novembro de 2017. Agradecem à Fundação Cearense de Apoio ao Desenvolvimento Científico e Tecnológico e à UNILAB, pelo financiamento através do Edital PROPPG 01/2019 BICT/FUNCAP, com vigência de 01/08/2019 a 31/07/2020. Agradecem à Unilab, através da PróReitoria de Extensão, Arte e Cultura pelo financiamento através dos Editais PIBEAC 2020, 2019, 2018, 2016/2017 e 2015/2016, com vigência de julho de 2015 a dezembro de 2020. Os autores também agradecem ao financiamento dos projetos CAPES PGPSE Processo: 88887.123947/2016-00: Sistemas Ambientais costeiros e ocupação econômica do Nordeste; CAPES PRINT Processo 
Periferias urbanas, redes locais e movimentos sociais em fortaleza, ceará

88887.312019/2018-00: Integrated socio-environmental technologies and methods for territorial sustainability: alternatives for local communities in the context of climate change; e Programa CAPES/FUNCAP Proc. 88887.165948/2018-00: Apoio às Estratégias de Cooperação Científica do Programa de Pós-Graduação em Geografia - UFC. Agradecem ao CNPq por recursos associados à Bolsa Produtividade. Agradecem ao Programa de Pós-Graduação em Geografia da UFC. Por fim, também agradecem à Rede de Desenvolvimento Local, Integrado e Sustentável do Grande Bom Jardim.

\section{Referências}

AGIER, Michel. Do direito à cidade ao fazer a cidade: o antropólogo, a margem e o centro. Mana, v. 21, n. 3, p. 483-498, 2015.

ALMEIDA, Adriano Paulino. (Grande) Bom Jardim: reterritorialização e política de representação à luz da nova pragmática. 2014. Dissertação (Mestrado em Linguística Aplicada) - Centro de Humanidades, Programa de Pós-Graduação em Linguística Aplicada, Universidade Estadual do Ceará, Fortaleza, 2014.

ALONSO, Angela. As teorias dos movimentos sociais: um balanço do debate. Lua Nova, São Paulo, v. 76, p. 49-86, 2009.

BARROS, Laura Pozzana; KASTRUP, Virgínia. Cartografar é acompanhar processos. In: PASSOS, Eduardo, KASTRUP, Virgínia; ESCÓSSIA, Liliana da. (Org.). Pistas do método da cartografia: pesquisa-intervenção e produção de subjetividade. Porto Alegre: Sulina, 2015. p. 52-75.

BRAUDEL, Ferdinand. História e Ciências Sociais: a longa duração. Revista da História, v. 30, n. 16, p. 261-294, 1965.

CARLOS, Euzeneia. Contribuições da análise de redes sociais às teorias de movimentos sociais. Revista de Sociologia e Política, Curitiba, v. 19, n. 39, p. 153-166, jun. 2011. 
Periferias urbanas, redes locais e movimentos sociais em fortaleza, ceará

CARLOS, Caio Anderson Feitosa. Invenções democráticas pela periferia: a rede desenvolvimento local, integrado e sustentável do Grande Bom Jardim. 2014. 200 f. Dissertação (Mestrado em Sociologia) - Programa de Pós-Graduação em Sociologia, Universidade Federal do Ceará, 2014.

CEFAÏ, Daniel. Como nos mobilizamos? A contribuição de uma abordagem pragmatista para a sociologia da ação coletiva.

Dilemas: Revista de Estudos de Conflitos e Controle Social, v. 2, n. 4, p. 11-48, 2009.

CEFAÏ, Daniel. Públicos, problemas públicos, arenas públicas: o que nos ensina o pragmatismo (Parte 1). Novos Estudos CEBRAP, São Paulo, v. 36, n. 1, p. 187-213, 2017.

DIANE, Mario. The concept of social movement. The Sociological Review, n. 92, p. 1-25, 1992.

DIANE, Mario; BISON, Ivano. Organizations, coalitions, and movements. Theory and Society, v. 33, p. 281-309, 2004.

IBGE. Instituto Brasileiro de Geografia e Estatística. Tabela 3175: População residente, por cor ou raça, segundo a situação do domicílio, o sexo e a idade. Brasília: IBGE, 2010. Disponível em: https://sidra.ibge.gov.br/Tabela/3175. Acesso em: 15 jul. 2019.

IBGE. Instituto Brasileiro de Geografia e Estatística. Cidades: Fortaleza. Brasília: IBGE, 2019. Disponível em: https://cidades. ibge.gov.br/brasil/ce/ fortaleza/panorama. Acesso em: 15 jan. 2020.

MACHADO, Eduardo Gomes. Desafios da intervenção acadêmica no planejamento urbano: diálogos sociológicos com a educação popular em Paulo Freire. In: OLIVEIRA, Elaine Ferreira Rezende de; GABARRA, Larissa Oliveira e; LOPES, Leandro de Proença. (Org.). Construindo pontes: Paulo Freire entre saberes, projetos e continentes. Fortaleza: EDUECE, 2018. p. 77-100. (v. 1). 
Periferias urbanas, redes locais e movimentos sociais em fortaleza, ceará

MACHADO, Eduardo Gomes. Desigualdades e segregações socioespaciais em Fortaleza, Brasil: uma análise a partir da Praia do Futuro. O Público e o Privado, v. 30, p. 179-208, 2017.

MACHADO, Eduardo Gomes. Planejamento Urbano, democracia e participação popular: o caso da revisão do Plano Diretor de Fortaleza (2003-2008). 2011. 451 f. Tese (Doutorado em Sociologia) - Programa de Pós-Graduação em Sociologia, Universidade Federal do Ceará, Fortaleza, 2011.

MACHADO, Eduardo Gomes; FAUSTINO, Anna Erika Rocha. Perfil da rede de desenvolvimento local, integrado e sustentável do Grande Bom Jardim (Rede DLIS do GBJ). Relatório de Pesquisa. Fortaleza: Rede de Desenvolvimento Local e Sustentável do Grande Bom Jardim (Rede DLIS), 2018.

MARQUES, Gabriel Garcia. Cem anos de solidão. 48. ed. São Paulo; Rio de Janeiro: Record, 1967.

MELUCCl, Alberto. Um objetivo para os movimentos sociais? Lua Nova, n. 17, p. 49-66, 1989.

MOURA, Gyl Giffony Araújo. A construção da memória social como política pública: o caso do Centro Cultural Bom Jardim, em Fortaleza, Ceará. 2012. 179 f. Dissertação (Mestrado em Memória Social) - Programa de Pós-Graduação em Memória Social, Universidade Federal do Estado do Rio de Janeiro, Rio de Janeiro, 2012.

PAIS, José Machado. Sociologia da vida quotidiana: teorias, métodos e estudos de caso. Lisboa: Imprensa de Ciências Sociais, 2015.

REDE DLIS. Rede de Desenvolvimento Local e Sustentável do Grande Bom Jardim. Pacto Territorial pelo Desenvolvimento Humano. Fortaleza, 2003.

SAQUET, Marcos Aurélio. Abordagens e concepções entre territórios. 3. ed. São Paulo: Outras Expressões, 2013. 
Periferias urbanas, redes locais e movimentos sociais em fortaleza, ceará

Eduardo Gomes Machado • Alexandre Queiroz Pereira

SOUZA, Marcelo Lopes de. "Território" da divergência (e da confusão): em torno das imprecisas fronteiras de um conceito fundamental. In: SAQUET, Marcos Aurélio; SPÓSITO, Eliseu Savério. (Org.). Territórios e territorialidade: teorias processo e conflitos. São Paulo: Expressão Popular; UNESP; Programa de PósGraduação em Geografia, 2009. p. 37-56.

TATAGIBA, Luciana; PATERNIANI, Stella Zagatto; TRINDADE, Thiago Aparecido. Ocupar, reivindicar, participar: sobre o repertório de ação do movimento de moradia de São Paulo. Opinião Pública, v. 18, n. 2, p. 399-426, nov. 2012.

TILLY, Charles. Movimentos sociais como política. Revista

Brasileira de Ciência Política, Brasília, n. 3, p. 133-160, jan./jul. 2010.

\section{Declaração de contribuição individual}

Todos os autores ofereceram substanciais contribuições científicas e intelectuais ao estudo. As tarefas de concepção e design do estudo, preparação e redação do manuscrito, desenvolvimento teórico-conceitual, bem como aquisição de dados e suas interpretações e análise foram desenvolvidas em grupo. Os procedimentos técnicos de revisão, normalização e tradução do artigo foram realizados por profissionais certificados, conforme declarações também anexadas ao processo de submissão.

Eduardo Gomes Machado - Possui graduação em Ciências Sociais pela Universidade Estadual do Ceará (1998), Mestrado em Sociologia pela Universidade Federal da Paraíba (2002) e Doutorado em Sociologia pela Universidade Federal do Ceará (2011). Atualmente é Professor Associado I da Universidade da Integração Internacional da Lusofonia Afro-Brasileira (UNILAB). ORCID: https://orcid.org/0000-0002-9321-6745 
Periferias urbanas, redes locais e movimentos sociais em fortaleza, ceará Eduardo Gomes Machado • Alexandre Queiroz Pereira

Alexandre Queiroz Pereira - Possui Graduação em geografía pela Universidade Estadual do Ceará. Mestrado e Doutorado em geografía pela Universidade Federal do Ceará. Atualmente é professor Adjunto no Departamento de Geografia da Universidade Federal do Ceará e Professor Visitante da Le Mans Université França. ORCID: https://orcid.org/0000-0001-7560-6064

Recebido para a publicação em 19 de fevereiro de 2020 Aceito para a publicação em 2 de abril de 2020 Publicado em 7 de maio de 2020 